\title{
Cognition, Health, and Well-Being in a Rural Sub- Saharan African Population
}

\author{
Collin F. Payne ${ }^{1}$ - Iliana V. Kohler ${ }^{2}$ Chiwoza Bandawe B $^{3}$ \\ Kathy Lawler ${ }^{4} \cdot$ Hans-Peter Kohler ${ }^{5}$
}

Received: 13 August 2016/Accepted: 16 September 2017/Published online: 7 November 2017

(C) Springer Science+Business Media B.V. 2017

\begin{abstract}
Cognitive health is an important dimension of well-being in older ages, but few studies have investigated the demography of cognitive health in sub-Saharan Africa's growing population of mature adults (= persons aged $45+$ ). We use data from the Malawi Longitudinal Study of Families and Health to document the age and gender patterns of cognitive health, the contextual and life-course correlates of poor cognitive health, and the understudied linkages between cognitive and physical/mental well-being. Surprisingly, the age pattern of decline in cognitive
\end{abstract}

Electronic supplementary material The online version of this article (doi:10.1007/s10680-017-94451) contains supplementary material, which is available to authorized users.

Collin F. Payne

cpayne@hsph.harvard.edu;

http://www.collinfpayne.com

Iliana V. Kohler

iliana@pop.upenn.edu

Chiwoza Bandawe

cbandawe@gmail.com

Kathy Lawler

Kathy.Lawler@uphs.upenn.edu

Hans-Peter Kohler

hpkohler@pop.upenn.edu;

http://www.ssc.upenn.edu/ hpkohler

1 Center for Population and Development Studies, Harvard University, Cambridge, MA 02138, USA

2 Population Studies Center, University of Pennsylvania, Philadelphia, PA 19104, USA

3 Department of Mental Health, College of Medicine, Blantyre, Malawi

4 Department of Neurology, Perelman School of Medicine University of Pennsylvania, Philadelphia, PA 19104, USA

5 Department of Sociology, University of Pennsylvania, Philadelphia, PA 19104, USA 
health is broadly similar to that observed in the USA. We also find that women have substantially worse cognitive health than men and experience a steeper age gradient in cognitive ability. Strong social ties and exposure to socially complex environments are associated with higher cognitive health, as is higher socioeconomic status. Poor cognitive health is associated with adverse social and economic well-being outcomes such as less nutrition intake, lower income, and reduced work efforts even in this subsistence agriculture context. Lower levels of cognitive health are also strongly associated with increased levels of depression and anxiety and are associated with worse physical health measured through both self-reports and physical performance. Our findings suggest that cognition plays a key-but understudiedrole in shaping late-life well-being in low-income populations.

Keywords Cognitive health · Aging · Sub-Saharan Africa · Mental health · Physical health

Why are some persons maintaining high levels of cognitive abilities at older ages, while others experience cognitive decline, various forms of dementia, and other memory loss as they age? This variability in the level of cognitive health and its pace of decline with age is pervasive, and its determinants have received extensive attention by researchers, policy makers, and providers of elderly care. For example, a recent National Academy of Science Report calls for a societal commitment to cognitive aging as a public health issue that requires prompt action across many sectors (Blazer et al. 2015). Importantly, the need to address cognitive health $(\mathrm{CH})$ as a major public health concern is no longer restricted to high-income countries. Longer life expectancies and lower fertility have given rise to growing aging populations in low- and middle-income countries (LMICs) (United Nations Population Division 2015), and by 2050 over $70 \%$ of global dementia cases are expected to occur outside of high-income countries (Prince et al. 2013).

Despite the importance of $\mathrm{CH}$ for shaping well-being at older ages, there exists a large knowledge gap about $\mathrm{CH}$ among older individuals in LMICs. This knowledge gap is at its widest in sub-Saharan Africa (SSA) as very few population-based studies of aging and cognition exist (Lekoubou et al. 2014). Yet, there are reasons to suspect that, in SSA, CH may be particularly salient in shaping individual wellbeing at older ages. Poor $\mathrm{CH}$ is seen as an important factor contributing to persistent global health and income inequality (Hanushek and Woessmann 2008), and older individuals in SSA may play an important role in this link due to their almost universal labor force participation (International Labour Organization 2016), their pivotal caretaking roles in families affected by HIV/AIDS (Zagheni 2011; Zimmer and Teachman 2009), and their contributions to downward intergenerational transfers (Kohler et al. 2012; Lee and Mason 2011). SSA populations can ill-afford a productivity gap resulting from cognitive limitations among mature and older adults. In SSA, a high prevalence of poor $\mathrm{CH}$ is also likely to have substantial repercussions for individual well-being and day-to-day functioning, arguably even more so than in higher-income contexts, as the health services and infrastructure for addressing and ameliorating cognitive decline and related aspects of aging are vastly 
insufficient (Frost et al. 2015). The currently poor evidence basis on $\mathrm{CH}$ limits the ability of research to inform policies and health system investments that can help reduce the individual, familial, and social implications of poor $\mathrm{CH}$ among adult and older individuals.

The existing evidence about cognitive aging from high-income contexts, and the policy and health recommendations countries derived from this evidence, suggests that older adults in SSA may experience worse cognitive outcomes and accelerated cognitive aging: Older individuals in SSA have widely divergent life histories from those in high-income settings, including increased exposure to chronic undernutrition and infectious diseases, economic shocks, severe poverty, and high levels of uncertainty, all of which have been linked to reduced cognitive abilities and accelerated cognitive aging (Haan et al. 2011; Lynch et al. 1997; Madsen 2016). But there are also factors that might reduce cognitive decline among older individuals in SSA, either by being protective or increasing mortality selection, including lower levels of social isolation, lower levels of cognitive ability at adulthood, higher levels of physical activity, high levels of economic engagement even among older adults, and shorter life expectancies that imply strong mortality selection among survivors to old age. These and related factors might suggest that cognitive aging might not be as pronounced as has been documented in higher-income contexts (Ellwardt et al. 2013; Haslam et al. 2014; Salthouse 1991).

Although we have an understanding of the underlying contributors to cognitive aging from high-income contexts, the way that these contributors manifest themselves and affect cognitive aging may differ greatly in SSA LICs from the way they do in higher-income contexts. The pace of cognitive aging, the life-course and well-being correlates of cognitive aging, and the connections between cognition, physical health, and mental health may be very different in a SSA LIC context where social and environmental conditions are massively different from the previously studied high-income countries.

Hence, what is urgently needed is an evidence base for documenting $\mathrm{CH}$ among older individuals in SSA, and for understanding the determinants and correlates of cognitive aging among individuals who experienced life histories that are distinctly different from the extensively studied aging populations in high-income countries. For example: How variable is $\mathrm{CH}$ among mature and older adults in SSA, and how does it differ by gender? Does cognitive aging follow a different trajectory in low-income SSA countries than in more developed contexts? How are education and socioeconomic status associated with $\mathrm{CH}$ among the elderly in this context? Do closer family networks and increased social participation buffer against cognitive decline? And, what are the repercussions of poor $\mathrm{CH}$ for individual well-being, work efforts, depression, anxiety, and physical health in a poor SSA mature adult population?

\section{Background}

Cognition covers many mental abilities and processes, including decision making, memory, attention, and problem solving (Blazer et al. 2015). Cognitive ability refers to the ability of individuals to adequately perform cognitive tasks and processes and 
is determined by anatomy and physiology of the brain, sensory abilities, environmental conditions, and social processes. The ability to perform well on these multiple dimensions of cognition is defined as cognitive health, and adequate cognitive health has been shown to be critical for successfully engaging in the various activities involved in daily functioning (Moritz et al. 1995). Cognitive health also is an important factor in the development of functional impairments and physical disabilities (Fitzpatrick et al. 2007; Watson et al. 2010). Recent research has also highlighted the process of cognitive aging, defined as the gradual-yet highly variable - changes in cognitive functions that occur as people get older (Blazer et al. 2015), thereby adopting a dynamic life-course perspective rather than a static view of $\mathrm{CH}$. An important insight from cognitive aging research is that the decline in specific brain functions occurs independent of disease processes in the brain, such as neurodegeneration from Alzheimer's disease or stroke. The decrease in cognitive functioning is thus a hallmark of the broader aging process, and prospectively, cognitive health is a key predictor of aging processes in other domains and survival to older ages (Fitzpatrick et al. 2007).

Existing research on cognition in SSA has primarily focused on estimating the incidence and prevalence of dementia (Lekoubou et al. 2014). While understanding this prevalence is important, this research overlooks the wide range of cognitive abilities in the older population, the social determinants of CH in SSA, and the implications of variability in $\mathrm{CH}$ for day-to-day activities and well-being among older individuals. Moreover, the survey instruments used in these studies are designed mainly to capture clinical dementia (Guerchet et al. 2014; Paddick et al. 2015; Prince et al. 2011), rather than population-level variability of $\mathrm{CH}$. Dementia represents only a small subset of this population-level distribution of $\mathrm{CH}$, and our measures of $\mathrm{CH}$ have therefore been designed to capture the full range of $\mathrm{CH}$ present among older individuals in a SSA LIC.

While little research has addressed the determinants of this within-population variability in $\mathrm{CH}$ in SSA LMICs, related research from middle- and high-income countries offers potential clues. For example, social participation and group engagement have been related to better $\mathrm{CH}$, particularly at older ages (Ellwardt et al. 2013; Haslam et al. 2014; Thomas 2011), as has relatively high life-course socioeconomic status (Hurst et al. 2013; Staff et al. 2016). High levels of socioeconomic status in adulthood may mediate the relationship between early-life conditions and late-life cognitive function (Lyu and Burr 2016), but do not completely eliminate the effect of early-life adversities (Zhang et al. 2016). Higher levels of schooling and better schooling performance are also linked to both better $\mathrm{CH}$ and slower rates of cognitive aging (Cook and Fletcher 2015; Herd 2010), and this education-cognition nexus is possibly even more important in LMIC contexts than in high-income countries (Huang and Zhou 2013). Cognitive reserves, measuring the ability of individuals to cope better with adverse influences on $\mathrm{CH}$, have been shown to vary significantly among individuals, particularly at older ages and often as a function of individuals' life course (Stern 2009). 


\section{Data and Methods}

\subsection{Context}

Malawi is a relatively poor SSA country, ranked 174 of 187 in terms of the human development index (UNDP 2014). In rural areas, where the study population of the MLSFH is based, the majority of individuals engage primarily in home production of crops, complemented by some market activities. HIV/AIDS prevalence is $11 \%$ in the national population (Malawi DHS 2011), though HIV+ rates are much lower in the older population. This low HIV prevalence is largely due to high HIV-related mortality of these cohorts in early life (Freeman and Anglewicz 2012). Although HIV prevalence is fairly low at older ages, the HIV epidemic has great contextual importance to this population-older adults in Malawi lived through the peak of a widespread HIV epidemic (Payne and Kohler 2017), a traumatic process even for the HIV - population. Rural Malawians also live in conditions similar to other rural populations in SSA, characterized by high levels of poverty, episodic malnutrition, poor sanitation, a high prevalence of infectious diseases and endemic parasites, and limited access to healthcare facilities (Kohler et al. 2015). The Malawian population, similarly to other SSA countries, is also increasingly bearing the double burden of infectious diseases and non-communicable diseases (Msyamboza et al. 2011), with the latter now accounting for $28 \%$ of total deaths (WHO 2014). Older adults can expect to live a large proportion of their later years subject to physical limitations on their activities (Payne et al. 2013). The inability to carry out daily work due to physical and cognitive declines affects social participation and social acceptance of older individuals, and mature adults often express this as a major aging-related concern (Freeman 2016).

\subsection{Data}

The Malawi Longitudinal Study of Families and Health (MLSFH) (Kohler et al. 2015 ) is one of very few long-standing publicly available longitudinal cohort studies in a SSA LIC context with eight data collection rounds during 1998-2013 for up to 4000 individuals. The MLSFH is collected in three regions: Balaka in the south, Mchinji in the center, and Rumphi in the north. The MLSFH cohorts were selected to represent the rural population, where the majority of Malawians (85\%) live (WHO 2014). A "Cohort Profile" of the MLSFH, providing detailed discussion of MLSFH sampling procedures, survey methods, survey instruments, and analyses of attrition, has been published in the International Journal of Epidemiology (Kohler et al. 2015). In 2012-2013, the MLSFH mature adult survey focused explicitly on mental and cognitive health, non-communicable diseases, and their risk factors in the population aged $45+\left[\left(\right.\right.$ Kohler et al. 2017); $N_{2012}=1246$ with a mean age $=59.7 ; N_{2013}=1234$ with a mean age $\left.=61.0\right]$. Pertinent information and additional details on the MLSFH mature adult population are provided in Appendix Text A.1-A.3. 
In order to investigate how the age pattern of cognitive decline may be similar or different in rural Malawi compared to higher-income contexts, we rely on cognitive data from two nationally representative samples of older adults from the USA-the Midlife Development in the United States (MIDUS II) sample (Ryff and Lachman 2009) and the Cognition and Aging in the USA (CogUSA) national sample (McArdle et al. 2015). The MIDUS II sample represented a longitudinal follow-up of the original MIDUS cohorts and included the Brief Test of Adult Cognition by Telephone, an extensive battery of cognitive questions. The MIDUS II sample was aged from 35 to 84 at time of survey. The CogUSA study focused on measuring age-related changes in cognition and on the relationship between health and economic well-being and late-life cognition. The study population was designed to mirror that of the Health and Retirement Study (HRS). We use the in-person round of data collection from CogUSA (Wave 2) to compare age patterns of cognitive health with the MLSFH sample.

\subsection{Measures}

\subsubsection{Cognitive Assessment of Elderly Malawians}

Cognitive aging is not easily defined by clear thresholds on cognitive tests, particularly in environments where most established cognition scales are difficult to implement because of low schooling levels. This is especially the case in SSA, where the current evidence basis about $\mathrm{CH}$ is weak, and many factors-including culture, education, work activities, environmental context, and access to health care-are likely to influence test performance and norms (Busch et al. 2006; Chandra et al. 2014). Locally adapted measures and assessments of $\mathrm{CH}$ are therefore important, rather than merely an application of Western scales and cut-points. As the MLSFH was not able to implement an instrument previously validated in Malawi or a similar context, the team developed and pretested a comprehensive instrument designed to capture a wide range of cognitive abilities, spanning from high cognitive functioning to severe cognitive impairment. The survey instrument was also developed to be suitable for a little-schooled and partially illiterate study population, and implementable by well trained, albeit lay MLSFH interviewers (Details on survey implementation are available in Appendix Text A.1).

After extensive testing and development, the MLSFH implemented a modified version of the International Cognitive Assessment (ICA), a brief screening test designed to be relatively culture-free and appropriate for populations with limited access to formal schooling. It assesses six cognitive domains: basic language ability, orientation, visual/constructional skills, attention/working memory, executive functions, and delayed memory (recall/recognition). The maximum ICA score is 30, corresponding to highest (best) cognitive assessment. The full ICA questionnaire and details on how the ICA was modified for our study context are included as Appendix B, and additional details on ICA administration are included in Appendix Text A.2. Appendix Table 1 presents an overview of the summary statistics and correlations for the total ICA score and the sub-scores. 
Our analyses use each respondent's best ICA score between the two 2012-2013 MLSFH waves as our primary measure of $\mathrm{CH}$. With a 1-year gap between waves, the research team determined that relying on the higher of the two measures results in a more conservative and robust-to-measurement-error indicator of $\mathrm{CH}$. In addition, this approach allows us to limit the influence of practice effects in confounding our results-individuals in longitudinal studies often show improvement in cognitive tests between the first and second waves of data collection, due to increased familiarity with both the survey items and the experience of being tested (Jones 2015). There is no systematic trend in the wave of highest score: $46 \%$ of the highest ICA scores came from the 2012 interview and 54\% from the 2013 interview, and scores are strongly correlated $(r=0.65)$. A scatter plot comparing 2012 and 2013 ICA scores is included as Appendix Fig. 1. All analyses of the pooled 2012-2013 MLSFH adjusted for clustering within respondent; CH or cognitive ability is based on the best score from 2012 or 2013, and depending on the model specification, this best score is the used as dependent or as part of the explanatory analyses.

\subsubsection{Cognitive Ability Categories}

The ICA score is analyzed in two ways: as a continuous measure, allowing us to exploit the full variation in the ICA, and as a categorical measure that classifies ICA into five levels of cognitive ability. In lieu of pre-established and validated ICA classifications for our study context, our categorical analyses use the youngest subset of the 2012-2013 MLSFH respondents, i.e., respondents aged 45-54, to construct locally relevant thresholds for the classification of cognitive ability. These individuals are the least cognitively impaired in our sample, and at prime adult ages 45-54 years, they provide a suitable reference population for assessing $\mathrm{CH}$. Specifically, the ICA score is classified based on the distribution of highest score from the 2012-2013 MLSFH population aged 45-54 $(N=442)$, excluding HIV+ individuals $^{1}(N=28)$. Cognitive ability categories are as follows: The 25th percentile of this distribution is the cut-point for low cognitive ability, the 5th percentile is the cut-point for mild cognitive impairment, and the 1st percentile of this distribution is the cut-point for moderate to severe cognitive impairment. In addition, the 75th percentile of the distribution of 45-54-year-olds was used as a cut-point for high cognitive ability. Threshold ICA scores were 26.5 or above for high cognitive ability, 26-21 for average cognitive ability, 20.5-16 for low cognitive ability, 15.5-12 for mild cognitive impairment, and below 12 for moderate to severe cognitive impairment. To avoid contamination by using the same population to define and analyze the $\mathrm{CH}$ classification, all analyses using our categorical assessment of cognitive ability are restricted to the population 55+ (while our analyses of the continuous ICA score include all respondents aged 45+). Our findings are robust with respect to modification of this classification

\footnotetext{
${ }^{1}$ We chose to omit HIV+ individuals from the reference population as HIV infection has known associations with neurocognitive functioning (Antinori et al. 2007; Heaton et al. 2010; Lawler et al. 2010, 2011) and HIV is not distributed uniformly across age in this sample.
} 
scheme (see Appendix Materials). Appendix Table 2 also shows the comparison of the cognitive ability classification measure (estimated as described above) between the MLSFH, CogUSA, and MIDUS II samples; the proportion of individuals falling into each classification at each age is fairly similar across these three samples, thereby benchmarking the cognitive ability of older respondents to the contextspecific cognitive abilities of adults aged 45-54.

\subsubsection{Determinants and Correlates of Cognitive Health}

The MLSFH contains extensive measures of various determinants and correlates of $\mathrm{CH}$, including:

Social participation, social environment, and socioeconomic status The 2012 MLSFH asked a set of questions on social participation, including total membership in village groups, number of visits to the market in the past month, and number of social events attended in the past month (including dances, drama performances, political meetings, and funerals). These sorts of participatory activities have been linked with improved cognition in late life (Ellwardt et al. 2013; Hsu 2007), and group engagement in particular has previously shown strong and lasting effects with increasing age (Haslam et al. 2014). In addition, the total number of household members was measured, as well as the total number of the respondent's children living in the same household or same village. These measures all relate to the social complexity of an individual's environment, which is known to be strongly associated with cognition and cognitive decline in later life (Seeman et al. 2001).

Long-term socioeconomic status (SES) The MLSFH has collected information on the roofing material of each household in the survey since 2001, and thus our analyses can test for differences in $\mathrm{CH}$ among individuals who have experienced different trajectories in household SES. Additional income is very often used to improve housing in Malawi, so a change in roof material from nonmetal to metal acts as a strong proxy for a rise in household wealth. (For example, in a 2012 survey of MLSFH interviewers-who are drawn from the rural regions represented in the study-70\% of interviewers (20 of 29) reported using their previous MLSFHrelated earnings on repairing or adding to their homes.) In addition to roofing material, individuals' height is also an often-used proxy for childhood nutrition status and is thus a reliable marker of childhood SES (Maurer 2010; Weir et al. 2014). The MLSFH collected height measurements in 2012 and 2013, and we test the association between height (measured in centimeters) and ICA score to gain insight into the relationship between early-life conditions and later-life cognitive health in the MLSFH sample.

Social and economic wellbeing outcomes Protein intake (important in the Malawian context characterized by frequent food shortages and crises) was measured as the number of days in the last week with chicken, fish, or meat consumption. Respondents reported their total earnings in the past 12 months; this variable was transformed using the inverse hyperbolic sine transformation to normalize the income distribution and account for individuals with zero reported earnings (Burbidge et al. 1988). Binary indicators for any reported earnings and any 
reported savings were additionally tested. Total work efforts are measured as the total number of hours of farm and household work reported in the past week.

Subjective life satisfaction and mental health In 2012 and 2013, the MLSFH collected subjective well-being as well as multiple measures of mental health (see Kohler et al. 2017, for a detailed discussion). Subjective life satisfaction was based on the question: "How satisfied are you with your life, all things considered?", with responses ranging from $1=$ very unsatisfied to $5=$ very satisfied. Depression and anxiety were measured with the PHQ9 and GAD7 modules of the Patient Health Questionnaire (PHQ) (Kroenke et al. 2010), where higher scores denote worse depression and anxiety. The MLSFH additionally collected the SF-12 health survey (Gandek et al. 1998), from which the SF-12 mental health score was derived. Lower SF-12 mental health scores denote worse overall mental health. The SF-12, PHQ9, and GAD7 scores are used in our analyses as continuous outcomes.

Physical health General self-rated health was reported as $1=$ poor to $5=\mathrm{ex}$ cellent. Respondents were also asked if they had accomplished less or had work limitations due to physical health over the past 4 weeks, with responses ranging from $1=$ none of the time to $5=$ all of the time. Frequency of pain interfering with work was measured with responses from $1=$ not at all to $5=$ extremely. Indicators of physical health measured in the 2012-2013 MLSFH include body mass index (BMI), grip strength (in $\mathrm{kg}$ ), and systolic blood pressure (2013 only).

\subsection{Analyses}

The association between ICA score and baseline characteristics was estimated using linear regression, and the marginal means of $\mathrm{CH}$ outcomes were estimated in age-, gender-, and schooling-specific strata based on linear regressions of the total ICA score on a cubic function of age with controls for region and MLSFH wave. Analyses of attrition among the MLSFH mature adult population are provided in Appendix Text A.4.

The associations between ICA score and measures of social environment, social participation, and socioeconomic status were estimated using multivariate regression. Regressions were used to estimate the associations between $\mathrm{CH}$-measured as continuous ICA score and as cognitive ability categories-and individual wellbeing, mental health, and physical health. Differences in this relationship by gender-that is, whether the relationship between ICA score and economic wellbeing, mental health, and physical health differed between men and women-were tested using a female $\times$ ICA interaction term. All analyses were pooled across the 2012 and 2013 MLSFH mature adult survey, and where appropriate, standard errors were adjusted for clustering within respondents. All multivariate analyses control for age, age ${ }^{2}$, female, female $\times$ age, schooling, roof material, region, and MLSFH wave. Age was centered on its sample mean in all regressions, as was the continuous ICA score. 


\section{Results}

\subsection{Descriptive Analysis}

Columns 1-3 of Table 1 present the baseline summary statistics of the MLSFH mature adult sample in 2012. The mean age of respondents was about 60 , with a

Table 1 Sample characteristics and baseline associations with ICA score for the MLSFH study population aged $45+$ in 2012

\begin{tabular}{|c|c|c|c|c|}
\hline & $\begin{array}{l}(1) \\
\text { Females } \\
\text { Mean } \\
(\mathrm{SD})\end{array}$ & $\begin{array}{l}(2) \\
\text { Males } \\
\text { Mean } \\
(\mathrm{SD})\end{array}$ & $\begin{array}{l}(3) \\
\text { Total } \\
\text { Mean } \\
(\mathrm{SD})\end{array}$ & $\begin{array}{l}\text { (4) } \\
\text { ICA score }\end{array}$ \\
\hline \# of observations & 711 & 535 & 1246 & \\
\hline Age & $\begin{array}{c}59.4 \\
(11.3)\end{array}$ & $\begin{array}{c}60.7 \\
(10.8)\end{array}$ & $\begin{array}{c}60.0 \\
(11.1)\end{array}$ & - \\
\hline Total ICA score & $\begin{array}{l}20.4 \\
(5.2)\end{array}$ & $\begin{array}{l}23.4 \\
(4.4)\end{array}$ & $\begin{array}{l}21.7 \\
(5.1)\end{array}$ & - \\
\hline \multicolumn{5}{|l|}{ Age group } \\
\hline $45-54$ & 0.42 & 0.33 & 0.38 & Ref. \\
\hline $55-64$ & 0.29 & 0.34 & 0.31 & $-0.91 * *$ \\
\hline $65-74$ & 0.17 & 0.21 & 0.19 & $-3.26 * *$ \\
\hline $75+$ & 0.12 & 0.12 & 0.12 & $-6.24 * *$ \\
\hline \multicolumn{5}{|l|}{ Education level } \\
\hline No formal education & 0.48 & 0.20 & 0.36 & Ref. \\
\hline Primary & 0.50 & 0.68 & 0.58 & $2.83 * *$ \\
\hline Secondary or higher & 0.02 & 0.11 & 0.06 & $5.51 * *$ \\
\hline \multicolumn{5}{|l|}{ Region } \\
\hline Central (Mchinji) & 0.31 & 0.29 & 0.30 & Ref. \\
\hline South (Balaka) & 0.34 & 0.39 & 0.37 & 0.27 \\
\hline North (Rumphi) & 0.34 & 0.32 & 0.33 & $0.57^{+}$ \\
\hline Metal/tile roof & 0.30 & 0.32 & 0.31 & $0.93 * *$ \\
\hline Muslim & 0.28 & 0.26 & 0.27 & -0.38 \\
\hline Currently married & 0.63 & 0.95 & 0.77 & 0.33 \\
\hline HIV positive & 0.04 & 0.05 & 0.05 & 0.26 \\
\hline Female & - & - & 0.57 & $-1.92 * *$ \\
\hline Constant & & & & $21.7 * *$ \\
\hline \multicolumn{5}{|l|}{ Cognitive ability classification (age $55+$ only) } \\
\hline High ability (ICA $\geq 26.5$ ) & 8.6 & 27.3 & 17.2 & \\
\hline Average ability (ICA range 21-26) & 27.7 & 42.4 & 34.4 & \\
\hline Low ability (ICA range 16-20.5) & 36.7 & 21.0 & 29.5 & \\
\hline Mild impairment (ICA range 12-15.5) & 14.1 & 5.7 & 10.3 & \\
\hline Moderate to severe impairment (ICA < 12) & 12.9 & 3.6 & 8.6 & \\
\hline
\end{tabular}

Column 4 reports the coefficients of a multivariate regression of ICA score on respondent characteristics ${ }^{+} p<0.10 ; * p<0.05 ; * * p<0.01$ 
similar age distribution between men and women. Schooling attainment was relatively low and varied substantially by gender, as most of the sample would have been of schooling age over 40 years ago when access to schooling was limited in rural areas and substantial gender differences prevailed in schooling expectations in Malawi (Banda 1982). Just over 30\% of the sample population lived in a household with a metal or tile roof, and about $30 \%$ of our sample is Muslim. Almost all the men in the MLSFH population were currently married, in contrast to only about $60 \%$ of the women (a 2/3 majority of the non-married are widowed, with the remainder being divorced or separated). Only about $5 \%$ of the study population tested $\mathrm{HIV}+$, reflecting earlier high levels of adult mortality among the HIV+ members of these cohorts. Similar distributions across the study population are observed in 2013.

Column 4 presents regression coefficients of a multivariate regression of total ICA score on baseline sample characteristics. Increasing age is associated with declines in $\mathrm{CH}$, with cognitive decline accelerating at older ages. Formal schooling is strongly associated with higher total ICA score. The combined regression suggests that women have significantly lower ICA scores even after controlling for differences in exposure to formal schooling. Living in a household with a metal or tile roof was associated with higher ICA score, though Muslim religion and marital status were not. Overall, there do not appear to be any systematic differences in total ICA score between the HIV - and HIV + populations, though the sample size of the $\mathrm{HIV}+$ population is quite small $(34 \mathrm{HIV}+$ men and $38 \mathrm{HIV}+$ women). The remainder of our analyses will combine the HIV+ and HIV- populations and control for HIV status, though all of our key findings hold in analyses restricted to the HIV- sample.

Our categorical measure of cognitive ability indicates a substantial burden of poor $\mathrm{CH}$ in our study population (bottom pane of Table 1), particularly among women. There are substantial gender differences in cognitive ability classificationonly $36 \%$ of women have average or high cognitive ability (ICA score $\geq 21$ ), compared with $70 \%$ of men. About $30 \%$ of the sample is classified as having low cognitive ability. (ICA scores range from 16 to 20.5.) About $19 \%$ of the sample have mild or moderate to severe cognitive impairment, though again these proportions are substantially higher for women (27\%) than for men (10\%).

\subsection{Age Patterns of ICA Score}

Panel A of Fig. 1 depicts the gender-specific age pattern of total ICA score, documenting a general decline in $\mathrm{CH}$ with age. The figure indicates a strong gender gap and a widening of gender differences with age. Declines in $\mathrm{CH}$ with age are substantial: The average ICA score for a 70-year-old woman is about 4 points lower than that of a 55-year-old woman (corresponding to 1.2 times the standard deviation of the ICA score among 45-55-year-olds), with smaller age declines observed among men. Panel B of Fig. 1 indicates that the standard deviation rises steadily with age, and this increase is stronger among men than among women. Panel $\mathrm{C}$ of Fig. 1 indicates that $\mathrm{CH}$ differs substantially by schooling attainment, and individuals with more schooling appear to delay their cognitive decline. 
A

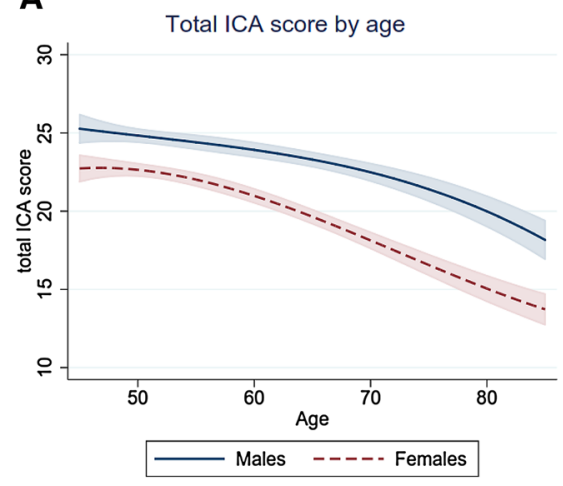

C

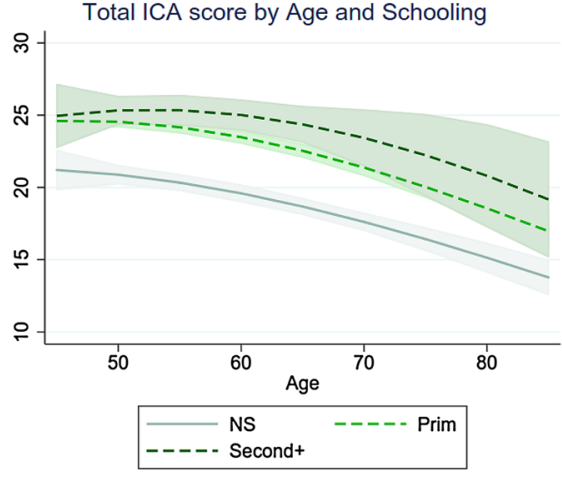

With controls for region and sex
B

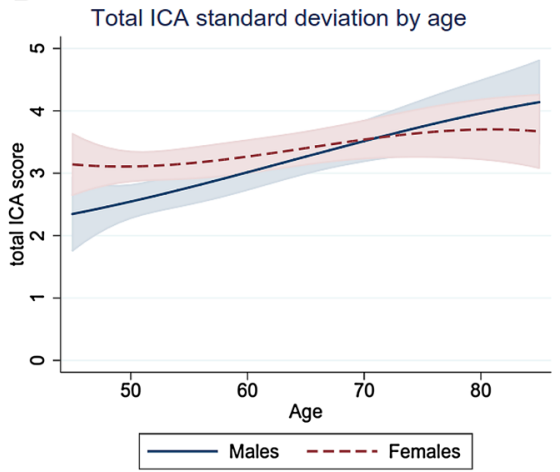

D

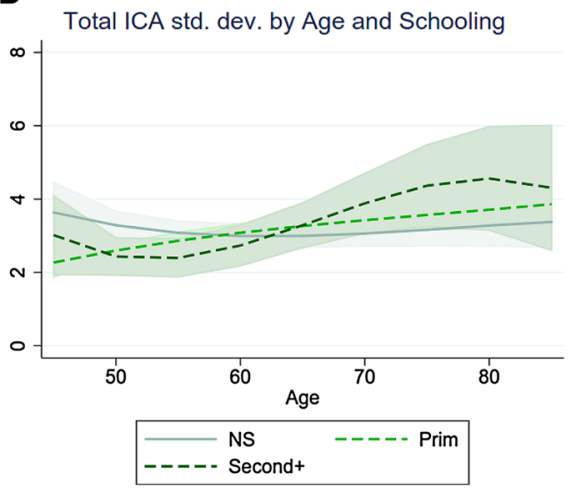

With controls for region and sex

Fig. 1 Total ICA score by sex and level of schooling (MLSFH sample). NS no schooling, Prim some primary schooling (1-7 years), Second + some secondary or more $(8+$ years $)$

The lifelong exposure to adverse conditions among our study participants might suggest a more rapid decline in $\mathrm{CH}$ than among individuals in high-income countries. While a definite test of this hypothesis requires longitudinal data on $\mathrm{CH}$, which will be available in the future, a comparison of cross-sectional $\mathrm{CH}$ patterns suggests that this is not necessarily the case. Specifically, Fig. 2 shows a comparison between the MLSFH and the two US samples in the overall age pattern of z-scored summary indices of cognition-the Brief Test of Adult Cognition by Telephone from the MIDUS II sample (Ryff and Lachman 2009), and an index combining scores for six domains of the Woodcock-Johnson Psychoeducational Test Battery with the most overlap with the ICA - auditory working memory, number series, picture vocabulary, retrieval fluency, spatial relations, and visual matching score-from the CogUSA national sample (McArdle et al. 2015). Patterns in average $\mathrm{CH}$ (left panel) are quite similar between the two US samples and the MLSFH sample-all three populations see a marked and steady decline in cognitive $z$-score by age. Differences mainly arise in the standard deviation by age: Variability around the 

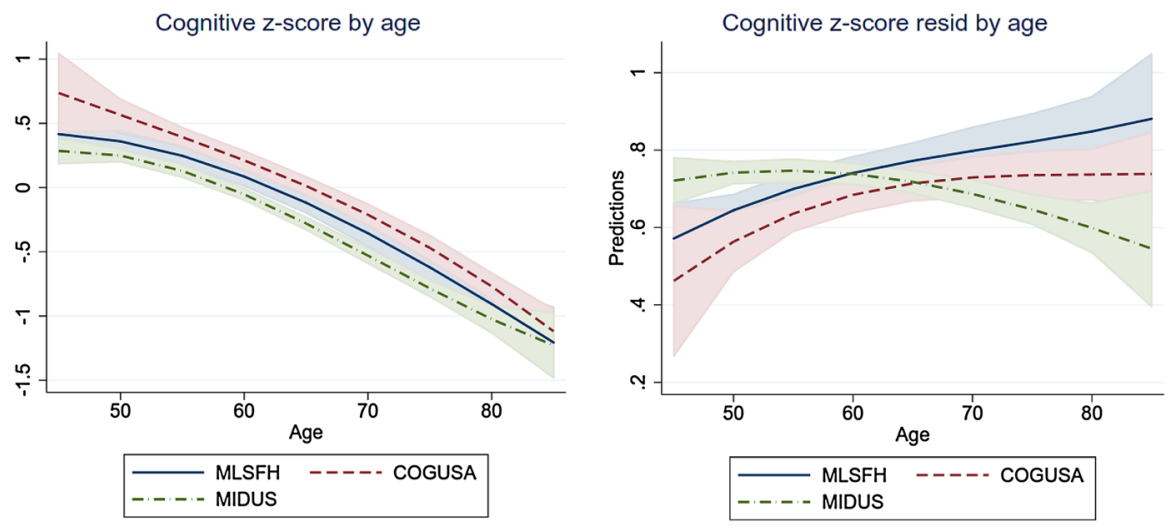

Fig. 2 Comparison of $z$-scored cognitive indices from MLSFH, CogUSA, and MIDUS II

mean increases with age in the MLSFH and CogUSA samples, but declines slightly in the MIDUS II sample.

To explore within-population variation in the rate of cognitive decline by age, Table 2 reports analyses of the ICA age gradient, allowing for differences in the ICA age gradient by schooling, gender, and roof material. The age $\times$ female interaction term (Column 2) shows that $\mathrm{CH}$ declines more rapidly for women, with women experiencing a $40 \%$ steeper age gradient than men. This results in the widening gender gap among older individuals (Fig. 1a). Having any schooling is associated with higher ICA scores (Table 1, Column 4), but we find no support for significant schooling $\times$ age $($ Column 4$)$ or schooling $\times$ roof material (Column 5) interactions. Appendix Table 3 tests for gender differences in the effect of schooling and roof material, as well as a three-way interaction between gender, schooling, and

Table 2 Linear age gradient in ICA score (MLSFH sample)

\begin{tabular}{lccccc}
\hline & $(1)$ & $(2)$ & $(3)$ & $(4)$ & $(5)$ \\
\hline Age gradient (change in CH per year of & $-0.21^{* *}$ & $-0.17^{* *}$ & $-0.16^{* *}$ & $-0.16^{* *}$ & $-0.16^{* *}$ \\
age) & $(0.011)$ & $(0.017)$ & $(0.018)$ & $(0.017)$ & $(0.017)$ \\
Female $\times$ age gradient & & $-0.069^{* *}$ & $-0.060^{* *}$ & $-0.067^{* *}$ & $-0.058^{* *}$ \\
& & $(0.022)$ & $(0.023)$ & $(0.022)$ & $(0.022)$ \\
Schooling $\times$ age gradient & & 0.63 & 0.75 \\
& & & $(0.53)$ & & $(0.52)$ \\
Roof material $\times$ age gradient & & & 0.41 & 0.23 \\
\end{tabular}

Analyses additionally control for region, schooling, roof material, and wave. Analyses are pooled across 2012 and 2013 MLSFH mature adult survey, and standard errors are adjusted for clustering within respondents

${ }^{+} p<0.10 ; * p<0.05 ; * * p<0.01$ 
age. There are no significant differences in the effect of these variables between men and women.

\subsection{Association Between ICA Score, Social Environment, Social Participation, and Socioeconomic Status}

Table 3 presents the associations between measures of an individual's current social environment and their ICA score, controlling for sample characteristics. Column 1 tests two measures of an individuals' social environment-the total number of people living in their household, and the number of own children sharing the household or living within the same village. The number of own children living nearby is positively and significantly associated with total ICA score, though larger household size is not associated with ICA. Column 2 tests three measures of social participation: number of social events attended in the past month (drama performances, dances, political meetings, and funerals), number of visits to the market in the past month, and total membership in village groups and committees. Increased market attendance and participation in village groups/committees are associated with substantially higher $\mathrm{CH}$. These activities are strongly participatory-negotiating prices, purchasing goods, and participating in village governance are all complex and demanding process. Simply attending social events does not appear to be associated with $\mathrm{CH}$, however. All of these associations remain in the regression combining the measures of social environment and social participation (Column 3).

Table 3 Multivariate associations between ICA score, social environment, and social participation (MLSFH sample)

(1)

Total household size

Number of proximate children ${ }^{\mathrm{a}}$

Social events attended past month

Visits to market past month

Village group memberships

Observations

1190

(2)

(3)

0.038
$(0.050)$
$0.097^{+}$
$(0.052)$
-0.012
$(0.022)$
$0.072 * *$
$(0.016)$
$0.22 * *$
$(0.081)$
90

Analyses additionally control for age, $\mathrm{age}^{2}$, female, region, schooling, roof material, wave, and a female $\times$ age interaction. Analyses are pooled across 2012 and 2013 MLSFH mature adult survey, and standard errors are adjusted for clustering within respondents

${ }^{+} p<0.10 ; * p<0.05 ; * * p<0.01$

${ }^{a}$ Proximate children are defined as own children living within the same household or village as the respondent 
The long-term associations between changes in SES and $\mathrm{CH}$ are presented in Table 4. Information back to 2001 is available for the subset of the MLSFH sample who were enrolled at the start of the MLSFH, but is not available for the MLSFH parent sample which was added in 2008 (see Kohler et al. 2015 and Appendix A.1 for details on the sample). Current household SES is strongly associated with ICA score-living in a household that transitions from having a thatch or mud roof in 2001 to a metal roof in 2012 (Column 1), or living in a household with a metal roof at both waves, is associated with a 0.8 point increase in total ICA score compared to an individual with a nonmetal roof at both waves. Column 2 tests whether duration of exposure to a high-SES environment was associated with higher ICA scores. Each additional year of living in a metal-roofed house was associated with a 0.09 point increase in ICA score. Similar associations are present when looking at the full 2008-2012 MLSFH mature adult sample with a shorter time horizon-living in a household that gains or retains a metal roof is associated with a higher ICA score compared to those with a nonmetal roof at both waves or those who move from a dwelling with a metal roof to one without (Column 3). Similarly, we find a strong and significant association between height and ICA score (Column 4), with a 10-cm increase in adult height associated with about a half-point higher total ICA score. This suggests that a portion of the variation in late-life health is likely due to childhood nutritional conditions and early-life SES.

\subsection{Association of Cognitive Score with Well-Being}

Table 5 reports the average predicted level of each outcome variable across the fivecategory cognitive ability classification based on marginal effects at the means (MEMs) estimated from multivariate regression models investigating the

Table 4 Association between ICA score and long-term socioeconomic status (MLSFH sample)

\begin{tabular}{lllll}
\hline & $(1)$ & $(2)$ & $(3)$ & $(4)$ \\
Years included & $2001-2012$ & $2001-2012$ & $2008-2012$ & $2012-2013$ \\
\hline $\begin{array}{l}\text { Change in roof material } \\
\text { Nonmetal at both waves }\end{array}$ & Ref. & & Ref. \\
Metal to nonmetal & $-^{\mathrm{a}}$ & & 0.027 \\
Nonmetal to metal & $0.83^{* *}$ & & $0.89^{* *}$ & \\
Metal at both waves & $0.80^{+}$ & & $0.87^{* *}$ & \\
Years with metal roof & & $0.088^{*}$ & & $0.051^{* *}$ \\
Height (cm) & & & 1246 & 1234 \\
Observations & 805 & 805 & & \\
\hline
\end{tabular}

Analyses additionally control for age, age ${ }^{2}$, female, region, schooling, wave, and a female $\times$ age interaction. Analyses are pooled across 2012 and 2013 MLSFH mature adult survey, and standard errors are adjusted for clustering within respondents

${ }^{+} p<0.10 ; * p<0.05 ; * * p<0.01$

${ }^{a}$ Due to low cell size $(n<10)$, this group was removed from the final analysis 
Table 5 Predicted means of protein intake, earnings, savings, and work efforts over cognitive ability classification

\begin{tabular}{llllll}
\hline & $\begin{array}{l}\text { Protein } \\
\text { intake }\end{array}$ & $\begin{array}{l}\text { Earnings in } \\
\text { past year } \\
\text { (logged Kw) }\end{array}$ & $\begin{array}{l}\text { Any labor } \\
\text { earnings past } \\
\text { year }\end{array}$ & Any savings & $\begin{array}{l}\text { Work } \\
\text { efforts (h) }\end{array}$ \\
\hline $\begin{array}{l}\text { Cognitive ability classification } \\
\text { High ability }\end{array}$ & 3.25 & 9.96 & 0.91 & 0.52 & 19.7 \\
{$[95 \% \mathrm{CI}]$} & {$[2.98,3.51]$} & {$[9.45,10.5]$} & {$[0.87,0.95]$} & {$[0.44,0.61]$} & {$[17.3,22.2]$} \\
Average ability & 2.84 & 9.71 & 0.92 & 0.38 & 19.2 \\
{$[95 \% \mathrm{CI}]$} & {$[2.65,3.03]$} & {$[9.36,10.1]$} & {$[0.89,0.94]$} & {$[0.33,0.44]$} & {$[17.5,20.9]$} \\
Low ability & 2.7 & 9.46 & 0.9 & 0.34 & 19 \\
{$[95 \% \mathrm{CI}]$} & {$[2.49,2.90]$} & {$[9.04,9.88]$} & {$[0.87,0.93]$} & {$[0.28,0.40]$} & {$[17.3,20.7]$} \\
Mild impairment & 2.46 & 8.87 & 0.88 & 0.26 & 13.6 \\
{$[95 \% \mathrm{CI}]$} & {$[2.11,2.81]$} & {$[8.17,9.57]$} & {$[0.83,0.93]$} & {$[0.17,0.35]$} & {$[10.7,16.4]$} \\
Mod. to sev. impairment & 2.32 & 7.6 & 0.77 & 0.21 & 16 \\
{$[95 \% \mathrm{CI}]$} & {$[1.93,2.71]$} & {$[6.51,8.69]$} & {$[0.67,0.87]$} & {$[0.087,0.33]$} & {$[12.4,19.7]$} \\
Observations & 746 & 748 & 748 & 748 & 748 \\
\hline
\end{tabular}

Analyses additionally control for age, age $^{2}$, female, region, schooling, roof material, wave, and a female $\times$ age interaction. Analyses are pooled across 2012 and 2013 MLSFH mature adult survey, and standard errors are adjusted for clustering within respondents. Regression coefficients are available in Appendix Table 4

association of $\mathrm{CH}$ with indicators of individual social/economic well-being. Main results for three alternative parameterizations of ICA categories are included as Appendix Tables 10-12. Individuals with moderate to severe impairment and mild impairment have substantially lower protein intake-on the order of one fewer day per week with high-quality protein consumption for moderately to severely impaired individuals compared to those in the high-ability classification. More impaired individuals also had lower earnings and lower savings rates and were far less likely to have any savings for the future. Work efforts are substantially lower for those with mild impairment, and holding all demographic factors at their sample means, individuals with mild impairment reported an average of 6.1 fewer hours per week of work effort in their own household or farm compared to those with average cognitive ability. Work efforts were also lower in the moderately/severely impaired and low-ability groups compared to those with average or high ability, though these differences were not universally significant. Individuals classified as having high cognitive ability had significantly higher protein consumption and substantially higher odds of having savings, but high cognitive ability was not associated with higher work efforts or earnings compared to those with average cognitive ability. The full table of regression coefficients is included as Appendix Table 4, and estimates from a regression model using the full MLSFH mature adult sample (45+) with continuous ICA score as a predictor are included as Appendix Table 5. 


\subsection{Association of Cognitive Health with Well-Being and Mental Health}

Table 6 provides average predicted level of self-rated life satisfaction and three mental health outcomes (PHQ9 depression score, GAD7 anxiety score, and the SF12 mental health index) over the levels of cognitive ability, based on MEMs using the same methodology and specification as in Table 5.

Subjective well-being is significantly lower among individuals with cognitive impairments compared to those with average cognitive ability. All levels of cognitive impairment are found to be significantly associated with worse mental health. Mild impairment is associated with almost a 60\% increase in PHQ9 score over individuals with average ability, and moderate to severe impairment is associated with a near-doubling of PHQ9 score. Given that a score of 5 or more represents a diagnosis of mild depression, these findings suggest that cognitive impairment and depressive symptoms are very closely linked in this population. Mild and moderate to severe impairment are also associated with substantially higher GAD7 scores, again a quite substantial increase given that a score of 5 or higher is interpreted as having mild anxiety. Poorer $\mathrm{CH}$ is also strongly associated with worse SF-12 mental health scores. Individuals in the low cognitive ability classification have, on average, also significantly worse mental health scores than those with average cognitive ability. Though lower levels of cognitive ability are associated with worse subjective well-being, more depression, higher anxiety symptoms, and poorer overall mental health, high cognitive ability does not appear

Table 6 Predicted means of subjective life satisfaction, depression (PHQ9), anxiety (GAD7), and SF-12 mental health scores over cognitive ability classification

\begin{tabular}{|c|c|c|c|c|}
\hline & $\begin{array}{l}\text { Life } \\
\text { satisfaction }\end{array}$ & $\begin{array}{l}\text { PHQ9 depression } \\
\text { score }\end{array}$ & $\begin{array}{l}\text { GAD7 anxiety } \\
\text { score }\end{array}$ & $\begin{array}{l}\text { SF-12 mental health } \\
\text { score }\end{array}$ \\
\hline \multicolumn{5}{|c|}{ Cognitive ability classification } \\
\hline High ability & 3.58 & 2.65 & 2.32 & 54.7 \\
\hline$[95 \% \mathrm{CI}]$ & {$[3.45-3.71]$} & {$[2.05,3.24]$} & {$[1.89,2.75]$} & {$[53.1,56.4]$} \\
\hline Average ability & 3.58 & 2.81 & 2.55 & 53.2 \\
\hline$[95 \% \mathrm{CI}]$ & {$[3.49-3.67]$} & {$[2.42,3.19]$} & {$[2.28,2.81]$} & {$[52.2,54.2]$} \\
\hline Low ability & 3.32 & 3.53 & 2.94 & 51.1 \\
\hline$[95 \% \mathrm{CI}]$ & {$[3.22-3.41]$} & {$[3.06,4.00]$} & {$[2.64,3.25]$} & {$[49.9,52.3]$} \\
\hline Mild impairment & 3.25 & 4.9 & 4.23 & 48.1 \\
\hline$[95 \% \mathrm{CI}]$ & {$[3.09-3.40]$} & {$[4.03,5.77]$} & {$[3.58,4.87]$} & {$[46.1,50.1]$} \\
\hline $\begin{array}{l}\text { Mod. to sev. } \\
\text { impairment }\end{array}$ & 2.91 & 5.43 & 4.33 & 48.1 \\
\hline$[95 \% \mathrm{CI}]$ & {$[2.70-3.11]$} & {$[4.18,6.68]$} & {$[3.49,5.17]$} & {$[44.8,51.5]$} \\
\hline Observations & 748 & 740 & 748 & 745 \\
\hline
\end{tabular}

Analyses additionally control for age, age ${ }^{2}$, female, region, schooling, roof material, wave, and a female $\times$ age interaction. Analyses are pooled across 2012 and 2013 MLSFH mature adult survey, and standard errors are adjusted for clustering within respondents. Regression coefficients are available in Appendix Table 6 
to have any protective effects - those with high ICA scores do not have substantially better well-being or mental health compared to those with average cognitive ability. The full table of regression coefficients is included as Appendix Table 6, and Appendix Table 7 contains complementary regression estimates using total ICA score as a continuous variable.

\subsection{Association of Cognitive Health with Physical Health}

Table 7 provides the average predicted level of six markers of physical health over the cognitive ability classification. Two types of health outcomes are used: selfreports of subjective physical health (self-rated health, work limitations due to physical health, pain interfering with work efforts), and measured markers of physical health (grip strength, BMI, and systolic blood pressure). Nearly all physical health measures show a clear gradient with decreasing cognitive ability. Self-rated health, physical limitations on work and daily activities, pain, and grip strength are all significantly worse among those with cognitive impairments compared to those with average ability, and most are also significantly worse among those with low cognitive ability. Poorer $\mathrm{CH}$ is somewhat associated with lower BMI (in the subsistence agriculture context of rural Malawi where calorie deficiency is a pressing concern, higher BMI is a positive outcome), though this difference is only substantial for the low-ability and moderately to severely impaired groups. Individuals with high cognitive ability had better self-rated health and significantly higher grip strength. However, high ability does not appear to protect individuals from physical limitations - individuals with high cognitive ability reported comparable levels of physical and pain limitations on work activities to those with average ability. The full table of regression coefficients is included as Appendix Table 8, and Appendix Table 9 contains complementary regression estimates using total ICA score as a continuous variable.

\section{Discussion}

Cognitive health is increasingly recognized as an important dimension and integral part of global population health due to its centrality for individuals' well-being and social/economic activities (National Institute on Aging 2012). Yet, especially as populations are aging worldwide, poor cognitive health continues to be an insufficiently understood aspect of the global burden of disease (Murray et al. 2012). Poor cognitive health is also likely to have important implications for well-being, social participation, and overall economic development in LICs (Sosa et al. 2012).

Our analyses use one of the very few population-based studies of $\mathrm{CH}$ among older individuals in SSA, the 2012-2013 rounds of the Malawi Longitudinal Study of Families and Health (MLSFH), to provide a first picture of $\mathrm{CH}$ in a populationbased sample of older individuals in this context. Because our data are collected within a 1-year period, we cannot (yet) study the dynamic process of cognitive aging, as has been done with longitudinal studies in high-income countries. As a proxy for the cognitive aging process, however, our analyses study $\mathrm{CH}$ across age 


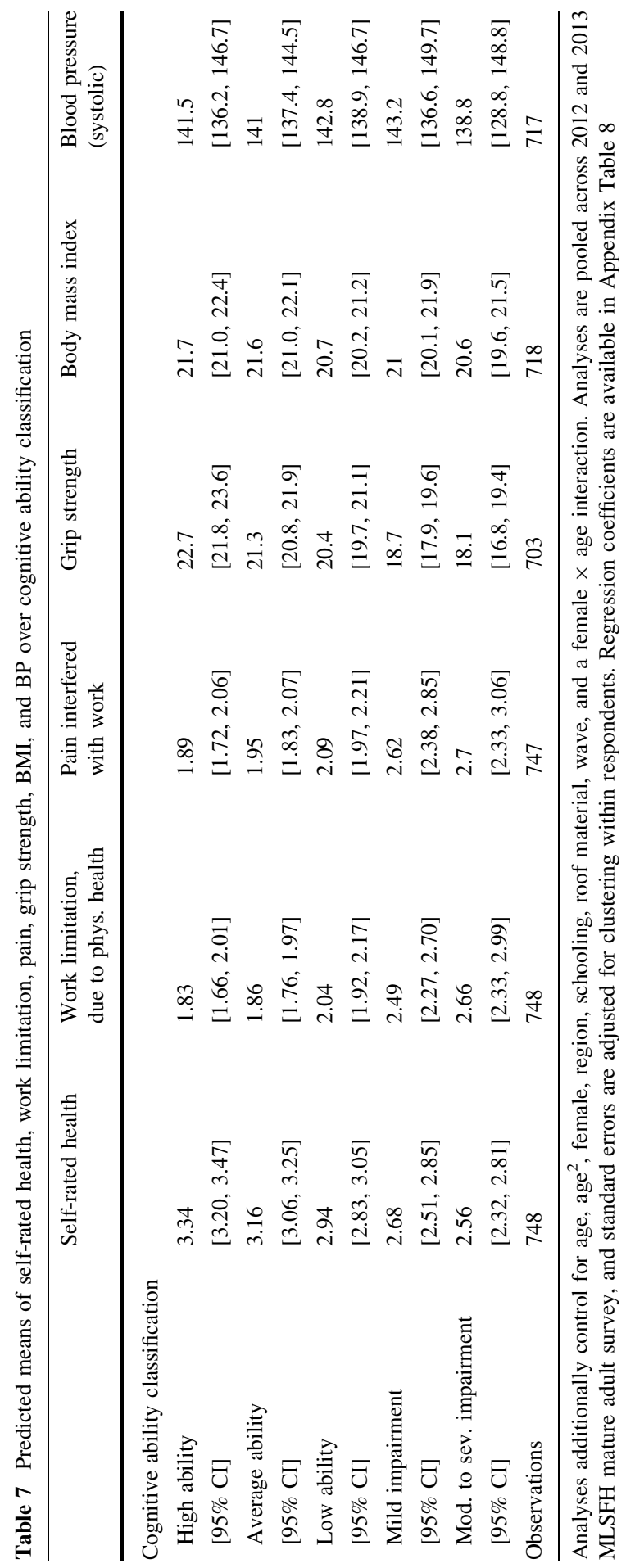


for mature and older adults. Our analyses also estimate the associations between the $\mathrm{CH}$ among mature and older adults and social and economic adversities, gender, family contexts, and life-course transitions. Given the general lack of knowledge about $\mathrm{CH}$ in SSA, these findings, even if they are descriptive in nature, are important in terms of highlighting the similarities and differences in $\mathrm{CH}$ patterns and correlates between SSA low-income countries and high-income countries where most current research is based. Moreover, by focusing on an important understudied population, our analyses implement the recommendations of the recent National Academy of Science Report (Blazer et al. 2015) that stressed the need to collect and disseminate population-based data on cognitive aging across a wide range of contexts, including high-risk and underserved populations from diverse contexts that have often been neglected in prior research.

Our findings also contribute to a small but growing literature on cognition and cognitive aging in lower-income contexts. The HRS network of sister studies has made substantial investments in collecting detailed cognitive data in forthcoming survey waves in countries such as India, China, Brazil, South Africa, and Mexico (RAND 2015), and as such the evidence base on late-life cognition and cognitive aging in LMICs is poised to expand rapidly in coming years.

Our results show that many mature adults in rural Malawi experience poor $\mathrm{CH}$ and that $\mathrm{CH}$ declines substantially with age for both men and women. The agerelated pattern of decline in $\mathrm{CH}$ in the MLSFH sample is remarkably similar to the pattern seen in studies of cognition in the USA. Some differences in $\mathrm{CH}$ may have had their roots relatively early in life, as indicated by the association of formal schooling with better overall $\mathrm{CH}$ and a less-steep age gradient. In line with the research from other contexts, $\mathrm{CH}$ appears to be strongly associated with the "richness" of an individual's social environment-increasing presence of close social relationships and complex, participatory social activities such as market visits and village group memberships are associated with higher cognitive scores (Haslam et al. 2014). Both current and past socioeconomic statuses are strongly associated with the ICA score: Individuals living in wealthier households (those with a metal/ tile roof) had substantially higher ICA scores than those with nonmetal roofs, as did taller individuals (with height reflecting early-life nutritional status and SES). More time spent living in a high-SES household was also associated with higher ICA scores.

$\mathrm{CH}$ is closely intertwined with the day-to-day well-being of mature adults: $\mathrm{CH}$ is strongly associated with many key aspects of daily life such as physical and mental well-being, consumption, and productivity. Men and women with cognitive impairments have more symptoms of depression and anxiety, worse physical health outcomes, and substantially lower economic productivity and financial security. These negative outcomes of poor $\mathrm{CH}$ occur not only among the most cognitively impaired; even individuals with moderately lower cognitive ability have significantly lower subjective life satisfaction and self-rated health, higher symptoms of depression and anxiety, are more limited due to physical health, and have lower BMI than individuals with average cognitive ability. In line with research from higher-income contexts, we find strong associations between cognition and grip strength, though the $4.6 \mathrm{~kg}$ difference between the average ability group and the 
moderate to severely impaired is strong in magnitude compared to other studies (Alfaro-Acha et al. 2006; Blankevoort et al. 2013; Sternäng et al. 2016). Though low cognitive ability is associated with a wide variety of adverse outcomes, high cognitive ability is only moderately protective. Compared to those with average ICA performance, older individuals with high levels of cognitive functioning have a higher rate of savings, better nutritional intake, and better self-rated health and grip strength. However, having high cognitive ability does not appear to protect individuals from experiencing physical limitations or depression/anxiety symptoms any more than those with average ability.

Poor $\mathrm{CH}$ is much more frequent among women than among men, though controlling for schooling attainment reduces this gap. This finding is in line with other research on cognition and aging in LMICs that has found substantial gender differentials in cognitive decline (Lee et al. 2011, 2014; Lei et al. 2014; Maurer 2011; Zhang 2006). Despite the differences in levels, $\mathrm{CH}$ has similar associations with well-being, mental health, and physical health outcomes for both men and women.

Some limitations of our analyses are as follows: First, our measure of $\mathrm{CH}$ is not directly comparable to other pre-established scales of cognition-though the ICA addresses many of the same domains of $\mathrm{CH}$ as other scales, the study team made considerable adaptations to these measures to render them suitable for a lowliteracy, low-education rural SSA context. As such, our prevalence estimates for mild and moderate to severe cognitive impairment are not directly comparable to other contexts. Our cognitive ability measure is based on the distribution of ICA score from the youngest subset of the MLSFH study population, thereby benchmarking the cognitive ability of older individuals relative to that of adults aged 45-54 years. This context-specific approach has several advantages given that this is one of the first population studies of CH in a SSA LIC, but we acknowledge that our cognitive ability classifications are not based on clinically established and validated thresholds (though analyses of several varying threshold schema found very similar results, see Appendix Tables 10-12). Furthermore, the validity of our categorical cognitive ability classification is strongly suggested by the fact that both the overall trend in cognitive decline with age and the distribution of our categorical measure were similar to patterns observed in two major studies of old age cognition in the USA (see Fig. 2 and Appendix Table 2). The 1-year gap between MLSFH waves is also insufficient to estimate longitudinal age trajectories of $\mathrm{CH}$; future waves of data will be needed to understand the age dynamics of cognition and cognitive aging in this population.

Second, our analyses are purely associational. We cannot rule out the potential for reverse associations with many of our outcomes of interest and are not able to disentangle the causal ordering of these relationships. Forthcoming future waves of MLSFH data collection will be key for disentangling the relationships between SES, social participation, and $\mathrm{CH}$, as well as for identifying the causal ordering between changes in physical, mental, and cognitive health.

Despite these limitations, our findings suggest that cognition plays a substantial role in individual well-being in later life in low-income SSA contexts such as Malawi. Though the patterns of age-related decline in $\mathrm{CH}$ that we observe in SSA 
appear to be similar to that observed in high-income contexts, low $\mathrm{CH}$ is very strongly associated with a host of negative outcomes in this context, including substantially higher rates of depression and anxiety, worse physical health, and lower economic well-being. In a context with few social supports for aging individuals and a severely lacking health infrastructure, these declines in $\mathrm{CH}$ with age appear to have very strong repercussions for individual well-being.

Despite this association of poor $\mathrm{CH}$ with socioeconomic adversity and poor physical and mental health among MLSFH mature adults, $\mathrm{CH}$ has been a neglected dimension of overall health in SSA and other low-income countries by both academic and policy communities. Our analyses thus strengthen the voices in recent policy and research debates (Blazer et al. 2015) that the cognitive health of older populations represents an important dimension of overall health and well-being in SSA and that there is a strong need for policy responses and interventions targeted toward sustaining $\mathrm{CH}$ in older ages and supporting those with cognitive impairments.

Acknowledgements The first wave of the MLSFH was funded by the Rockefeller Foundation. Subsequent funding has been provided by the NICHD (Grants R01 HD053781, R01 HD/MH041713, R01 HD37276, R01 HD044228, R21 HD050652, R03 HD058976, R21 HD050652, R21 HD071471) and has been supported by pilot grants from the Population Studies Center (PSC), Population Aging Research Center (PARC), the Boettner Center for Pensions and Retirement Security, the Institute on Aging and the Center for AIDS Research (CFAR), all at the University of Pennsylvania, supported by among other sources NIH Grants NICHD R24 HD044964, NIA P30 AG12836, NIAID AI 045008. The project also received funding from the University of Pennsylvania Research Foundation. We are also grateful for pilot funding received through the Penn Center for AIDS Research (CFAR), supported by NIAID AI 045008, and the Penn Institute on Aging. Part of this research was also supported by the Swiss Agency for Development and Cooperation (SDC) and the Swiss National Science Foundation through the Swiss Programme for Research on Global Issues for Development (SFF R4d Programme, Grant Number: 400640_160374). NICHD R01HD053781 is the only grant that provided direct support for the writing of this manuscript.

\section{Compliance with Ethical Standards}

Conflict of interest The authors declare no competing interests, and the funders had no role in the design of the study, the analysis of the data, or the decision to present the results.

Ethical Approval The data collection and research conducted by MLSFH was approved by the Institutional Review Board (IRB) at the University of Pennsylvania and, in Malawi, by the College of Medicine Research Ethics Committee (COMREC) or the National Health Sciences Research Committee (NHSRC).

\section{References}

Alfaro-Acha, A., Snih, S. A., Raji, M. A., Kuo, Y.-F., Markides, K. S., \& Ottenbacher, K. J. (2006). Handgrip strength and cognitive decline in older Mexican Americans. Journals of Gerontology. Series A, Biological Sciences and Medical Sciences, 61, 859-865. doi:10.1093/gerona/61.8.859.

Antinori, A., Arendt, G., Becker, J. T., Brew, B. J., Byrd, D. A., Cherner, M., et al. (2007). Updated research nosology for HIV-associated neurocognitive disorders. Neurology, 69, 1789-1799. doi:10. 1212/01.WNL.0000287431.88658.8b. 
Banda, K. N. (1982). A brief history of education in Malaŵi. Lilongwe: Dzuka Publishing Company.

Blankevoort, C. G., Scherder, E. J. A., Wieling, M. B., Hortobágyi, T., Brouwer, W. H., Geuze, R. H., et al. (2013). Physical predictors of cognitive performance in healthy older adults: A cross-sectional analysis. PLoS ONE, 8, e70799. doi:10.1371/journal.pone.0070799.

Blazer, D. G., Yaffe, K., \& Liverman, C. T. (Eds.). (2015). Cognitive aging: Progress in understanding and opportunities for action. Washington, DC: National Academy Press.

Burbidge, J. B., Magee, L., \& Robb, A. L. (1988). Alternative transformations to handle extreme values of the dependent variable. Journal of the American Statistical Association, 83, 123-127. doi:10. $2307 / 2288929$.

Busch, R. M., Chelune, G. J., \& Suchy, Y. (2006). Using norms in neuropsychological assessment of the elderly. In D. K. Attix \& K. A. Welsh-Bohmer (Eds.), Geriatric neuropsychology: Assessment and intervention. New York: Guilford Publications.

Chandra, V., Ganguli, M., Ratcliff, G., Pandav, R., Sharma, S., Belle, S., et al. (2014). Practical issues in cognitive screening of elderly illiterate populations in developing countries. The Indo-US CrossNational Dementia Epidemiology Study. Aging Clinical and Experimental Research, 10, 349-357. doi:10.1007/BF03339881.

Cook, C. J., \& Fletcher, J. M. (2015). Can education rescue genetic liability for cognitive decline? Special Issue: Educational Attainment and Adult Health: Contextualizing Causality, 127, 159-170.

Ellwardt, L., Aartsen, M., Deeg, D., \& Steverink, N. (2013). Does loneliness mediate the relation between social support and cognitive functioning in later life? Social Science and Medicine, 98, 116-124. doi:10.1016/j.socscimed.2013.09.002.

Fitzpatrick, A. L., Buchanan, C. K., Nahin, R. L., DeKosky, S. T., Atkinson, H. H., Carlson, M. C., et al. (2007). Associations of gait speed and other measures of physical function with cognition in a healthy cohort of elderly persons. Journals of Gerontology. Series A, Biological Sciences and Medical Sciences, 62, 1244-1251.

Freeman, E. (2016). Understanding HIV-related stigma in older age in rural Malawi. Social Science and Medicine, 164, 35-43. doi:10.1016/j.socscimed.2016.07.006.

Freeman, E., \& Anglewicz, P. (2012). HIV prevalence and sexual behaviour at older ages in rural Malawi. International Journal of STD and AIDS, 23, 490-496. doi:10.1258/ijsa.2011.011340.

Frost, L., Navarro, A. L., Lynch, M., Campbell, M., Orcutt, M., Trelfa, A., et al. (2015). Care of the elderly: Survey of teaching in an aging sub-Saharan Africa. Gerontology and Geriatrics Education, 36, 14-29. doi:10.1080/02701960.2014.925886.

Gandek, B., Ware, J. E., Aaronson, N. K., Apolone, G., Bjorner, J. B., Brazier, J. E., et al. (1998). Crossvalidation of item selection and scoring for the SF-12 health survey in nine countries: Results from the IQOLA project. Journal of Clinical Epidemiology, 51, 1171-1178. doi:10.1016/S08954356(98)00109-7.

Guerchet, M., Mbelesso, P., Ndamba-Bandzouzi, B., Pilleron, S., Desormais, I., Lacroix, P., et al. (2014). Epidemiology of dementia in Central Africa (EPIDEMCA): Protocol for a multicentre populationbased study in rural and urban areas of the Central African Republic and the Republic of Congo. SpringerPlus, 3, 338. doi:10.1186/2193-1801-3-338.

Haan, M. N., Al-Hazzouri, A. Z., \& Aiello, A. E. (2011). Life-span socioeconomic trajectory, nativity, and cognitive aging in Mexican Americans: The Sacramento Area Latino Study on Aging. Journals of Gerontology. Series B, Psychological Sciences and Social Sciences, 66B, i102-i110. doi:10.1093/ geronb/gbq071.

Hanushek, E. A., \& Woessmann, L. (2008). The role of cognitive skills in economic development. Journal of Economic Literature, 46, 607-668. doi:10.1257/jel.46.3.607.

Haslam, C., Cruwys, T., \& Haslam, S. A. (2014). "The we's have it": Evidence for the distinctive benefits of group engagement in enhancing cognitive health in aging. Social Science and Medicine, 120, 57-66. doi:10.1016/j.socscimed.2014.08.037.

Heaton, R. K., Clifford, D. B., Franklin, D. R., Woods, S. P., Ake, C., Vaida, F., et al. (2010). HIVassociated neurocognitive disorders persist in the era of potent antiretroviral therapy CHARTER Study. Neurology, 75, 2087-2096. doi:10.1212/WNL.0b013e318200d727.

Herd, P. (2010). Education and health in late-life among high school graduates cognitive versus psychological aspects of human capital. Journal of Health and Social Behavior, 51, 478-496. doi: $10.1177 / 0022146510386796$.

Hsu, H. C. (2007). Does social participation by the elderly reduce mortality and cognitive impairment? Aging and Mental Health, 11, 699-707. doi:10.1080/13607860701366335. 
Huang, W., \& Zhou, Y. (2013). Effects of education on cognition at older ages: Evidence from China's great famine. Social Science and Medicine, 98, 54-62.

Hurst, L., Stafford, M., Cooper, R., Hardy, R., Richards, M., \& Kuh, D. (2013). Lifetime socioeconomic inequalities in physical and cognitive aging. American Journal of Public Health, 103, 1641-1648. doi:10.2105/AJPH.2013.301240.

Jones, R. N. (2015). Practice and retest effects in longitudinal studies of cognitive functioning. Alzheimer's and Dementia (Amsterdam), 1, 101-102. doi:10.1016/j.dadm.2015.02.002.

Kohler, I. V., Kohler, H.-P., Anglewicz, P., \& Behrman, J. R. (2012). Intergenerational transfers in the era of HIV/AIDS: Evidence from rural Malawi. Demographic Research, 27, 775-834.

Kohler, I. V., Payne, C. F., Bandawe, C., \& Kohler, H.-P. (2017). The demography of mental health among mature adults in a low-income, high-HIV-prevalence context. Demography. doi:10.1007/ s13524-017-0596-9.

Kohler, H.-P., Watkins, S. C., Behrman, J. R., Anglewicz, P., Kohler, I. V., Thornton, R. L., et al. (2015). Cohort profile: The Malawi Longitudinal Study of Families and Health (MLSFH). International Journal of Epidemiology, 44, 394-404. doi:10.1093/ije/dyu049.

Kroenke, K., Spitzer, R. L., Williams, J. B. W., \& Löwe, B. (2010). The patient health questionnaire somatic, anxiety, and depressive symptom scales: A systematic review. General Hospital Psychiatry, 32, 345-359. doi:10.1016/j.genhosppsych.2010.03.006.

Lawler, K., Jeremiah, K., Mosepele, M., Ratcliffe, S. J., Cherry, C., Seloilwe, E., et al. (2011). Neurobehavioral effects in HIV-positive individuals receiving highly active antiretroviral therapy (HAART) in Gaborone, Botswana. PLoS ONE, 6, 1156-1162. doi:10.1371/journal.pone.0017233.

Lawler, K., Mosepele, M., Ratcliffe, S., Seloilwe, E., Steele, K., Nthobatsang, R., et al. (2010). Neurocognitive impairment among HIV-positive individuals in Botswana: A pilot study. Journal of the International AIDS Society. doi:10.1186/1758-2652-13-15.

Lee, R. D., \& Mason, A. (2011). Generational economics in a changing world. Population and Development Review, 37, 115-142. doi:10.1111/j.1728-4457.2011.00380.x.

Lee, J., Shih, R. A., Feeney, K. C., \& Langa, K. M. (2011). Cognitive health of older Indians [WWW Document]. http://www.rand.org/pubs/working_papers/WR889.html. Accessed 6.6.16.

Lee, J., Shih, R., Feeney, K., \& Langa, K. M. (2014). Gender disparity in late-life cognitive functioning in India: Findings from the longitudinal aging study in India. Journals of Gerontology. Series B, Psychological Sciences and Social Sciences, 69, 603-611. doi:10.1093/geronb/gbu017.

Lei, X., Smith, J. P., Sun, X., \& Zhao, Y. (2014). Gender differences in cognition in China and reasons for change over time: Evidence from CHARLS. The Journal of the Economics of Ageing, 4, 46-55. doi:10.1016/j.jeoa.2013.11.001.

Lekoubou, A., Echouffo-Tcheugui, J. B., \& Kengne, A. P. (2014). Epidemiology of neurodegenerative diseases in sub-Saharan Africa: A systematic review. BMC Public Health, 14, 653. doi:10.1186/ 1471-2458-14-653.

Lynch, J. W., Kaplan, G. A., \& Shema, S. J. (1997). Cumulative impact of sustained economic hardship on physical, cognitive, psychological, and social functioning. New England Journal of Medicine, 337, 1889-1895. doi:10.1056/NEJM199712253372606.

Lyu, J., \& Burr, J. A. (2016). Socioeconomic status across the life course and cognitive function among older adults: An examination of the latency, pathways, and accumulation hypotheses. Journal of Aging and Health, 28, 40-67. doi:10.1177/0898264315585504.

Madsen, J. B. (2016). Barriers to prosperity: Parasitic and infectious diseases, IQ, and economic development. World Development, 78, 172-187. doi:10.1016/j.worlddev.2015.10.032.

Malawi DHS. (2011). Malawi demographic and health survey 2010 (final report). National Statistical Office (NSO) and ICF Macro., Zomba, Malawi, and Calverton, Maryland, USA.

Maurer, J. (2010). Height, education and later-life cognition in Latin America and the Caribbean. Economics and Human Biology, 8, 168-176. doi:10.1016/j.ehb.2010.05.013.

Maurer, J. (2011). Education and male-female differences in later-life cognition: International evidence from Latin America and the Caribbean. Demography, 48, 915-930. doi:10.1007/s13524-011-0048$\mathrm{X}$.

McArdle, J., Rodgers, W., \& Willis, R. (2015). Cognition and aging in the USA (CogUSA) 2007-2009. Inter-university Consortium for Political and Social Research. doi:10.3886/ICPSR36053.v1.

Moritz, D. J., Kasl, S. V., \& Berkman, L. F. (1995). Cognitive functioning and the incidence of limitations in activities of daily living in an elderly community sample. American Journal of Epidemiology, 141, 41-49. 
Msyamboza, K. P., Ngwira, B., Dzowela, T., Mvula, C., Kathyola, D., Harries, A. D., et al. (2011). The burden of selected chronic non-communicable diseases and their risk factors in Malawi: Nationwide STEPS survey. PLoS ONE, 6, e20316.

Murray, C. J. L., Vos, T., Lozano, R., Naghavi, M., Flaxman, A. D., Michaud, C., et al. (2012). Disabilityadjusted life years (DALYs) for 291 diseases and injuries in 21 regions, 1990-2010: A systematic analysis for the Global Burden of Disease Study 2010. Lancet, 380, 2197-2223. doi:10.1016/S01406736(12)61689-4.

National Institute on Aging (2012). Global health and aging (NIH Publication no. 11-7737). Bethesda: National Institute on Aging. Retrieved from https://www.nia.nih.gov/sites/default/files/2017-06/ global_health_aging.pdf.

Organization, International Labour (Ed.). (2016). World employment and social outlook: Trends 2016, world employment and social outlook. Geneva: International Labour Department.

Paddick, S.-M., Gray, W. K., Ogunjimi, L., Lwezuala, B., Olakehinde, O., Kisoli, A., et al. (2015). Validation of the identification and intervention for dementia in elderly Africans (IDEA) cognitive screen in Nigeria and Tanzania. BMC Geriatrics, 15, 53. doi:10.1186/s12877-015-0040-1.

Payne, C., \& Kohler, H.-P. (2017). The population-level impact of public-sector antiretroviral therapy rollout on adult mortality in rural Malawi. Demographic Research, 36, 1081-1108. doi:10.4054/ DemRes.2017.36.37.

Payne, C. F., Mkandawire, J., \& Kohler, H.-P. (2013). Disability transitions and health expectancies among adults 45 years and older in Malawi: A cohort-based model. PLoS Medicine, 10, e1001435. doi:10.1371/journal.pmed.1001435.

Prince, M., Acosta, D., Ferri, C. P., Guerra, M., Huang, Y., Jacob, K. S., et al. (2011). A brief dementia screener suitable for use by non-specialists in resource poor settings-The cross-cultural derivation and validation of the brief Community Screening Instrument for Dementia. International Journal of Geriatric Psychiatry, 26, 899-907. doi:10.1002/gps.2622.

Prince, M., Bryce, R., Albanese, E., Wimo, A., Ribeiro, W., \& Ferri, C. P. (2013). The global prevalence of dementia: A systematic review and metaanalysis. Alzheimer's and Dementia, 9(63-75), e2. doi:10.1016/j.jalz.2012.11.007.

RAND. (2015). RAND HRS around-the-world harmonization meeting. Bethesda, MD: RAND Corporation.

Ryff, C. D., \& Lachman, M. E. (2009). Midlife in the United States (MIDUS 2): Cognitive Project, 2004-2006. Inter-university Consortium for Political and Social Research. doi:10.3886/ ICPSR25281.v5.

Salthouse, T. A. (1991). Theoretical perspectives on cognitive aging (Revised ed.). Hillsdale, NJ: Psychology Press.

Seeman, T. E., Lusignolo, T. M., Albert, M., \& Berkman, L. (2001). Social relationships, social support, and patterns of cognitive aging in healthy, high-functioning older adults: MacArthur studies of successful aging. Health Psychology, 20, 243-255.

Sosa, A. L., Albanese, E., Stephan, B. C. M., Dewey, M., Acosta, D., Ferri, C. P., et al. (2012). Prevalence, distribution, and impact of mild cognitive impairment in Latin America, China, and India: A 10/66 population-based study. PLoS Medicine, 9, e1001170. doi:10.1371/journal.pmed. 1001170 .

Staff, R. T., Chapko, D., Hogan, M. J., \& Whalley, L. J. (2016). Life course socioeconomic status and the decline in information processing speed in late life. Social Science and Medicine, 151, 130-138. doi:10.1016/j.socscimed.2016.01.019.

Stern, Y. (2009). Cognitive reserve. Neuropsychologia, 47, 2015-2028. doi:10.1016/j.neuropsychologia. 2009.03.004.

Sternäng, O., Reynolds, C. A., Finkel, D., Ernsth-Bravell, M., Pedersen, N. L., \& Aslan, D. K. A. (2016). Grip strength and cognitive abilities: Associations in old age. Journals of Gerontology. Series B, Psychological Sciences and Social Sciences, 71, 841-848. doi:10.1093/geronb/gbv017.

Thomas, P. A. (2011). Trajectories of social engagement and limitations in late life. Journal of Health and Social Behavior, 52, 430-443. doi:10.1177/0022146511411922.

UNDP. (2014). Human development report 2014: Sustaining human progress-reducing vulnerabilities and building resilience. New York, NY: United Nations Development Programme.

United Nations Population Division. (2015). World population prospects (No. ESA/P/WP.241).

Watson, N. L., Rosano, C., Boudreau, R. M., Simonsick, E. M., Ferrucci, L., Sutton-Tyrrell, K., et al. (2010). Executive function, memory, and gait speed decline in well-functioning older adults. 
Journals of Gerontology. Series A, Biological Sciences and Medical Sciences. doi:10.1093/gerona/ glq111.

Weir, D., Lay, M., \& Langa, K. (2014). Economic development and gender inequality in cognition: A comparison of China and India, and of SAGE and the HRS sister studies. The Journal of the Economics of Ageing, 4, 114-125. doi:10.1016/j.jeoa.2014.08.002.

World Health Orginazation (WHO). (2014). Noncommunicable diseases country profiles 2014. Malawi. Retrieved from http://www.who.int/countries/mwi/en/.

Zagheni, E. (2011). The impact of the HIV/AIDS epidemic on kinship resources for orphans in Zimbabwe. Population and Development Review, 37, 761-783.

Zhang, Z. (2006). Gender differentials in cognitive impairment and decline of the oldest old in China. Journals of Gerontology. Series B, Psychological Sciences and Social Sciences, 61, S107-S115.

Zhang, Z., Hayward, M. D., \& Yu, Y.-L. (2016). Life course pathways to racial disparities in cognitive impairment among older Americans. Journal of Health and Social Behavior, 57, 184-199. doi:10. $1177 / 0022146516645925$.

Zimmer, Z., \& Teachman, J. (2009). Household composition among elders in sub-Saharan Africa in the context of HIV/AIDS. Journal of Marriage and Family, 71, 1086-1099. 